The Geneva Papers on Risk and Insurance, 22 (No. 82, January 1997) 60-68

\title{
Remarks on the American Risk Based Capital Model
}

\author{
by Brian K. Atchinson*
}

The NAIC is an organization of all the state insurance regulators from the 50 states, the District of Columbia and the four U.S. territories. It is the oldest association of state government officials in the United States. In 1996, the NAIC celebrated its 125th anniversary.

State insurance commissioners are charged with the duty of protecting consumer interests while practicing fair and reasonable regulation of the insurance industry. The most important duty of insurance commissioners is to help maintain the financial stability of the insurance industry - that is, to guard against insolvencies.

Among the greatest weapons against insolvency are the risk-based capital requirements. The risk-based capital system uses a formula that establishes the minimum amount of capital necessary for an insurance company to support its overall business operations, considering its size and risk profile. That amount is then compared to the company's actual statutory capital to determine whether a company is technically solvent. The formula results, in combination with the authority granted in the state's Risk-Based Capital for Insurers law, allows state regulators to intervene in a timely manner when a company fails to meet these minimum standards. Companies failing to meet the minimum capital standard developed by the formula are subject to increasingly stringent regulatory intervention, depending upon the degree to which they fail the minimum standard.

Currently, the establishment of capital and surplus standards that are risk-based is the subject of active study and debate. The intent of proponents of the risk-based capital approach is to establish formulas that reflect the types of risks that a company is writing. In principle, the imposition of risk-based capital and surplus standards has a clear attraction. Property-casualty insurers that present higher risks would be required to maintain greater levels of capital than their counterparts who present lower risks.

* President, National Association of Insurance Commissioners (NAIC) and Superintendent of Insurance, State of Maine. Presentation before the General Assembly of the Geneva Association, Bordeaux, June 7, 1996.

The author gratefully acknowledges the contribution of Michael Barth of the National Association of Insurance Commissioners. 
The NAIC's risk-based capital system, in effect, limits the amount of risk a company can take on by requiring higher amounts of capital for bearing higher amounts of risk. The risk factors for the NAIC's risk-based capital formula, which produces a Regulatory Minimum Risk-Based Capital, focuses on four major areas: asset risk, liability or underwriting risk, business risk and miscellaneous risk.

Asset risk encompasses the risk that asset values will be lower than expected. Examples include bond defaults and changes in the market value of common stock. An insurer holding a portfolio of high-quality bonds obviously has more stability in its investment earnings than an insurer holding junk bonds or exotic derivative securities. The risk-based capital charge for high-risk securities is commensurably higher. Figure 1 shows some examples of risk charges for various classes of assets typically found in a U.S. insurer's investment portfolio.

Figure 1: Sample of RBC charges for selected asset categories

\begin{tabular}{|l|c|}
\hline TYPE OF INVESTMENT & RBC FACTOR \\
\hline U.S. government bonds & 0.000 \\
Highest quality corporate bonds & 0.003 \\
Cash and short-term investments & 0.003 \\
High quality corporate bonds & 0.010 to 0.100 \\
Bonds in default on principle or interest & 0.300 \\
Mortgages and collateral loans & 0.050 \\
Unaffiliated common stock & 0.150 \\
Real estate & 0.100 \\
Partnerships and joint ventures & 0.200 \\
Reinsurance recoverables & 0.100 \\
Miscellaneous recoverables & 0.050 \\
\hline
\end{tabular}

Investment risk is a very important component of the total risk posture for large life insurers, but for most property-casualty companies, the major underlying risk is its liabilities. In 1995, U.S. property-casualty insurers reported nearly $\$ 400$ billion in loss and loss expense reserves on their balance sheets. This amount represents a best estimate of existing obligations. However, estimates are prone to error, and the estimation error differs significantly by line of business. Insurers holding long duration obligations are required to hold relatively more capital to support those estimation errors.

In addition, there is a delay between the time that an insurer winds up its calendar year and the time that a regulator is able to review its annual statement filing for that calendar year. Studies have shown that the major cause of insolvencies in property-casualty insurers is underpricing or underestimation of reserves. If an insurer is producing under-priced business during the calendar year just ending, it is likely that the insurer will keep producing that underpriced business well into the new year. Therefore, $\mathrm{RBC}$ also generates a surplus requirement prospectively by line of business.

Figure 2 shows the industry breakdown of total RBC for both life and non-life insurers. As this figure shows, for property-casualty insurers, the predominant risks are underestimation of the reserves and overestimation of the profitability of incoming business. Therefore, 
Figure 2: 1995 industry aggregate RBC by category (in \$ millions)

\begin{tabular}{|l|cc|cc|}
\hline Major category & $\begin{array}{c}\text { Life } \\
\text { industry }\end{array}$ & $\begin{array}{c}\% \text { of } \\
\text { total }\end{array}$ & $\begin{array}{c}\text { P\&C } \\
\text { industry }\end{array}$ & $\begin{array}{c}\% \text { of } \\
\text { total }\end{array}$ \\
\hline Asset risk & 57,366 & $65 \%$ & 62,578 & $39 \%$ \\
Underwriting risk & 17,356 & $20 \%$ & 96,683 & $61 \%$ \\
Reserves & & & 62,281 & $39 \%$ \\
Written premiums & 13,569 & $15 \%$ & 34,402 & $22 \%$ \\
Other & 88,291 & $100 \%$ & N/A & \\
Total & & & 159,261 & $100 \%$ \\
\hline
\end{tabular}

the lion's share of the total RBC generated by the $\mathrm{P} \& \mathrm{C}$ formula falls into the underwriting risk categories. Conversely, life insurers tend to generate relatively more asset risk. The fundamental differences in the risk posture faced by life and non-life insurers are the driving force behind differences in the basic formulas.

It is useful to note the difference between Real Risk-Based Capital and Regulatory Minimum Risk-Based Capital (see Figure 3). Since capital is basically assets minus liabilities, capital also can be thought of as the degree to which a company pledges its assets to guaranty its promises to other parties (that is, its liabilities).

Figure 3: the difference between risk-hased capital and regulatory minimum risk-hased capital

- Regulatory minimum standards are set at minimum levels so as to impose a floor level of safety on the operations of an insurance company.

- System allows companies maximum freedom as long as they are above the minimums.

- Minimizes market disruptions by non-management while still maintaining safety levels.

- Regulatory minimum risk-based capital standard makes comparisons between companies inappropriate.

Capital serves as a cushion against insolvency. Therefore, most companies that have relatively higher risk already carry relatively higher amounts of capital. Figure 4 shows a moving average of the surplus-to-assets ratio for 2,400 property-casualty insurers, arranged in ascending order by asset size. As companies grow larger and more diversified, their operating results tend to be relatively more stable. More stability in results usually translates to less need for capital, but that rule of thumb is frequently violated. Not all companies carry an amount of capital that would generally be considered prudent. The NAIC's risk-based capital system essentially sets minimum standards for a company's self-insurance against insolvency. Because these standards can, in effect, alter the normal business decisions of insurers in the market, they must be carefully established to have the maximum effectiveness while at the same time minimizing market disruptions. 
Figure 4: moving average of surplus to assets ratio for property-casualty insurers arranged in ascending asset size 1995 data

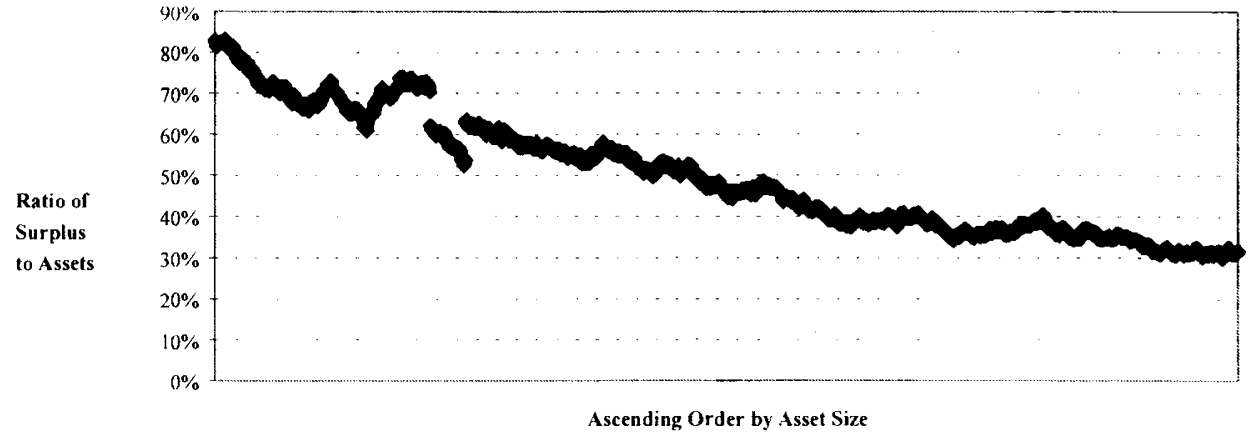

Real Risk-Based Capital is an economic concept. Companies hold the amount of capital that they perceive to be optimal or desirable. Regulatory Minimum Risk-Based Capital is a regulatory concept that sets a floor value for a company's own internally generated "optimal" or "desirable" capital decisions. Companies may hold any amount of capital in excess of the minimum established by law, but holding capital levels in excess of the regulatory minimums does not imply that a company is financially strong - it simply means that it is not weak as defined by the risk-based capital formula. A company's real Risk-Based Capital will almost always be higher than the Regulatory Minimum Risk-Based Capital, but it may not be enough and it may not be optimal. Therefore, the NAIC's risk-based capital standards are inappropriate as measures of financial strength and should never be used to compare one adequately capitalized company to another.

The purpose of computing risk-based capital is to help determine when and what actions regulators should take in the event a company's actual capital and surplus falls below its calculated minimum. Using the risk-based capital formula fits in with today's regulatory needs which require prompt, easily applied and easily understood measures.

To understand the need for a consistent and uniform approach, an historic overview is in order. In the late 1980 s there were a number of large insurer failures, and as a result, the importance of monitoring the financial soundness of insurance companies became even greater. So, in 1990, as part of the NAIC Solvency Policing Agenda, a working group was established to determine the feasibility of developing statutory, risk-based capital requirements for insurers. After conducting a thorough study and soliciting input from insurers and other interested parties, the working group concluded that risk-based capital requirements for insurers are preferable to the generally prevailing system of minimum capital and surplus requirements. The working group also determined that the purpose of establishing risk-based capital requirements would be to develop a more realistic capital base for insurers. It developed a formula and a companion NAIC model act that would provide the basis for treating insurers that did not meet the requirements.

Separate risk-based capital requirements for life-health and property-casualty were drafted. During 1991 and 1992, the appropriate requirements, instructions and models were developed. During the drafting process, extensive research was conducted and expert 
advice was sought from regulators, industry and consumers. The members of the NAIC adopted the life-health risk-based capital requirements in December 1992 and the propertycasualty requirements in December 1993.

Having a formula in place to compute uniform minimum capital standards for insurers is only part of the risk-based capital system, though. Regulators also need some legal basis to act. Prior to risk-based capital, a state regulator would have to petition the courts and try to prove that an insurer was operating in an unsound manner before being allowed to take decisive action. However, if the state has adopted some version of the Risk-Based Capital for Insurers Model Act, the regulator is granted the authority to act when an insurer triggers one of the intervention levels in the formula.

Generally, state insurance regulators concentrate their efforts on those companies domiciled in that state and rely on other state regulators to scrutinize those foreign insurers operating in their jurisdiction. Each state compares each of its companies' Total Adjusted Capital against that company's risk-based capital requirement to determine if regulatory action is warranted under that state's version of the Risk-Based Capital for Insurers Model Act. There are four intervention levels in the model act, but the Authorized Control Level Risk-Based Capital is the base standard against which Total Adjusted Capital is compared (see Figure 5).

Figure 5: Risk-Based Capital Levels

\begin{tabular}{|l|c|}
\hline Name of Risk-Based Capital (RBC) Level & $\begin{array}{c}\text { Percentage of Authorized } \\
\text { Control Level RBC }\end{array}$ \\
\hline Company Action Level RBC & 200 percent \\
Regulatory Action Level RBC & 150 percent \\
Authorized Control Level RBC & 100 percent \\
Mandatory Control Level RBC & 70 percent \\
\hline
\end{tabular}

Of the 2,419 property-casualty companies that submitted a risk-based capital report to the NAIC in 1995, 2,344 had sufficient capital to pass the RBC test. Once the test is passed, no further action is required. However, for the 3 percent of insurers that triggered some form of regulatory intervention, the RBC formula provides a spectrum of increasingly stringent regulatory responses. This allows the regulator to tailor an appropriate regulatory action to a company's financial problems, thus maintaining the maximum amount of discretion commensurate with prudent regulatory policies.

The first level of regulatory intervention in the RBC law is the Company Action Level. In 1995, 32 companies (about 1.3 percent of the total) triggered this level. When a company files a risk-based capital report indicating that its Total Adjusted Capital is higher than its Regulatory Action Level Risk-Based Capital but lower than its Company Action Level Risk-Based Capital, the insurer must submit to the insurance commissioner a comprehensive financial plan. That plan must identify the conditions in the insurer that contribute to the company's financial condition, contain proposals to correct the company's financial 
problems and provide projections of the company's financial condition, both with and without the proposed corrections. The plan also must list the key assumptions underlying the projections and identify the quality of, and problems associated with, the insurer's business.

When a company's Total Adjusted Capital falls between the Regulatory Action Level Risk-Based Capital and the Authorized Control Level Risk-Based Capital, or if the company fails to file a risk-based capital plan when required, the insurance commissioner shall perform any axaminations or analysis of the insurer's business and operations that he or she deems necessary and issue any appropriate corrective orders to address the company's financial problems. In 1995, 15 insurers ( 0.6 percent) triggered this level of intervention.

If the company's Total Adjusted Capital falls below the Authorized Control Level RiskBased Capital, in addition to those actions available to the insurance commissioner for less serious financial problems mentioned earlier, the commissioner may place the insurer under regulatory control. Only six insurers triggered this level in the $1995 \mathrm{RBC}$ filings submitted to the NAIC. Finally, if the company's Total Adjusted Capital falls below the Mandatory Control Level Risk-Based Capital, the insurance commissioner will be required to place the insurer under regulatory control. Twenty-two insurers (about 0.9 percent of the total) triggered this level in 1995. However, about half of the companies that trigger a Mandatory Control Level event are actually already insolvent - that is, they register negative surplus. Ideally, the RBC system will trigger one of the higher intervention levels first, and thus allow regulators an opportunity to work with the troubled insurer on a solution. However, with many smaller insurers, the first indication of financial impairment is also the last.

According to a 1996's February National Underwriter article, some United Kingdom regulators are studying the U.S. risk-based capital model and are moving ahead to develop their own system. Lloyd's of London has published its own proposal which requires that the risk-based formula parameters are made public, but the actual results of the calculations are confidential. Another company, Swiss Re, which is based in Zurich, is developing risk-based capital standards for all its subsidiaries. Eagle Star Re is moving forward on developing its own standards as well. The reason, according to one of its actuaries, is because "risk-based capital has done the U.S. insurance industry a lot of good, and I believe that insurance companies in Europe can only benefit from its introduction".

Fixed capital standards may have been adequate in the days when life companies issued plain vanilla policies with simple savings components and property-casualty companies simply wrote fire insurance. On the asset side, simple bonds, a few common stocks and some high quality mortgages generated stable streams of investment income. However, the world has changed and the insurance industry has changed even more rapidly. Today's life insurance company can write a wide array of complex products backed up by a bewildering portfolio of exotic investments that did not even exist just 10 years ago.

The nature of risk, both on the investment side and the underwriting side, has become extremely complex. Regulation has had to become more complex to meet the new solvency challenges while at the same time minimizing the amount of interference in legitimate business pursuits. Thus, regulators have had to move from relatively simple, one-size-fits-all fixed dollar capital standards to a new, fluid, flexible set of capital standards tailored to the risk profile of each individual company.

The EC countries use a formula approach coupled with fixed minimums to establish minimum capital standards for insurers, similar to the approach used by the members of the NAIC. The real difference lies in the degree of complexity. The diversity of insurers in the 
United States, coupled with the diversity of 55 different regulatory jurisdictions requires a set of common standards that recognize this great diversity. To the maximum extent possible, the NAIC formula has to recognize the unique risk profile of each individual company and set the minimum capital requirements commcnsurate with that risk.

While by no means a perfect formula, the NAIC's RBC formulas are a quantum leap toward capturing the unique solvency risk posed by each insurer. The NAIC formulas use company experience adjustment factors in portions of the calculation to recognize the relative experience of individual companies relative to their peers, tiered rating factors to recognize the decreasing risk of large insurance portfolios, and an overall covariance adjustment to recognize the effects of diversification and risk-spreading within a company's balance sheet.

The NAIC's risk-based capital system cannot alone prevent insolvencies. It can, however, help to alleviate insolvency costs by allowing insurance regulators to step in early while there is still a chance to save a dying company. Think of it as a wrench in the NAIC toolbox that can help stop a leaky faucet before it floods the entire house. It gives insurance regulators the flexibility to help prevent disasters before they occur.

One of the other reasons risk-based capital works so well in the U.S. is because it is part of another NAIC innovation that derived from the insurer failures in the 1980 s - the accreditation program.

The accreditation program also was designed to improve the quality of solvency regulation by state insurance departments. To ensure that regulation is adequate in all jurisdictions, the NAIC established the accreditation program to provide a baseline level of uniformity among the states to coordinate solvency monitoring. One of the requirements for accreditation is the adoption of the Risk-Based Capital for Insurers Model Act by the states. Independent review teams conduct thorough on-site reviews to evaluate a state's fitness for accreditation, and part of that review includes checking to see that each state has adopted the risk-based capital model by July 1, 1997.

Working along with the risk-based capital formula are a number of other tools used to monitor solvency. Examples of these tools include financial reporting, examination, and solvency screening systems such as the Insurance Regulatory Information System (IRIS) and the Financial Analysis and Solvency Tracking System (FAST). These tools are used more to identify higher-risk behavior, but unlike risk-based capital, they don't actually force an insurer to limit risk. Following are more details about each of these tools.

Designing a system that can identify insurers that are in, or are heading toward a hazardous condition is one of the greatest challenges that regulators face. The trick is to create a system that detects problems early enough so that they can be corrected, but doesn't raise false warnings about sound insurers. Financial reporting plays a large role in the solvency early warning system. The annual financial statement filed by insurers provides a relatively complete picture of financial condition. The statement has evolved considerably since being developed by the NAIC in 1875 to now include a balance sheet and income statement as well as a number of supporting exhibits and schedules. Most insurers also are required to file quarterly statements containing information on assets, liabilities, income, changes in investment holdings, premiums written, losses and reserves.

All of this information on individual insurance companies is amassed in an extensive financial database maintained by the NAIC. These databases are electronically accessible by 
state insurance departments and contain information on approximately 5,000 insurance companies dating back to the 1970s. The NAIC database serves as the core of the solvency surveillance and other analysis activities of state insurance regulators and the NAIC.

In addition, the NAIC maintains a number of other databases that state regulators use for financial analysis and other regulatory functions. The Alien Reporting Information System provides financial reports that show reinsurance ceded to domestic or alien reinsurers along with federal employer identification numbers, alien reinsurer identification numbers and reinsurer locations. The Regulatory Information Retrieval System contains information on completed regulatory actions against insurers and agents. The Special Activities Database is another source to check for market conduct information. These two databases enhance regulators' ability to share information on individuals or companies suspected of illegal or questionable activities, helping to prevent their infiltration into new areas.

Finally, examinations and risk scoring system tools help detect trouble spots. The basic purposes of an examination system are to detect as early as possible those insurers in financial trouble or engaging in unlawful activities and to develop the information needed for appropriate regulatory action.

Risk scoring models and other automated warning systems are used to allocate resources so examiners can concentrate on problem areas in a timely and efficient manner. A number of systems are used. The Insurance Regulatory Information System (IRIS) serves as a baseline solvency screening system for state regulators and the NAIC. IRIS helps regulators prioritize insurers for detailed financial analysis and allocate their resources according to need by producing a number of financial ratios. Examiners use the ratios and statements of insurers to determine if there is a need for further analysis by their domiciliary regulators.

Another system state regulators put to good use is the Financial Analysis and Solvency Tracking System (FAST). This system is an expansion of IRIS to encompass a new solvency screening model and analytical process to facilitate peer review of domiciliary regulation of "nationally significant" insurers. Its objective is to ensure that domiciliary regulators are taking effective action with respect to nationally significant insurers that are in financial difficulty. Nationally significant insurers are defined as companies that write business in 17 or more states and have gross premiums written in excess of $\$ 50$ million for life-health companies and $\$ 30$ million for property-casualty insurers. Like IRIS, FASTalso consists of a series of financial ratios based on annual statement data. However, FAST goes a step further and assigns different point values for different ranges of ratio results. A company's cumulative score is used to prioritize further analysis.

These are just a few of the things in the NAIC arsenal with regard to solvency monitoring. The NAIC continues to evaluate and refine capital requirements for all types of insurers and is taking the next step in protecting consumers through risk-based capital standards by developing standards for health organizations. The NAIC's Health Organizations Risk-Based Capital Working Group is drafting a separate risk-based capital formula for health insurance including traditional health insurers, health maintenance organizations (HMOs), Blue Cross/Blue Shield plans, and health service plans. The plan is to expand the provisions in the current life-health formula to better measure risk in various health organizations.

In fact, at the NAIC's September 1996 National Meeting, the working group received a preliminary report regarding a draft health risk-based capital formula from the American 
Academy of Actuaries. The working group is now testing the formula on health entities. Following the testing and evaluation, the working group will recommend a final version for adoption by the NAIC.

By working with industry, consumers and other interested parties over the years, the NAIC has developed valuable tools for state insurance regulators to use and monitor the solvency of insurers. As the 21st century approaches, it is obvious that significant changes in the structure of the insurance industry will continue to challenge the way that regulators do business. New technologies will continually and dramatically change the way we monitor insurers' insolvency risk.

The goal is for insurance regulators to continue to do their best to ensure that insurance companies do the best they can to provide their product to consumers. State regulators in the United States, through the NAIC, have done an admirable job of regulating insurance for 125 years and plan on building on our great track record into the next century and beyond. 